\title{
Naked bodies, naked genomes: the special (but not exceptional) nature of genomic information
}

\author{
Daniel P. Sulmasy, MD, PhD'
}

Genetic exceptionalism, the view that genomic information is different from other types of sensitive information and deserves exceptional types of protections, has been roundly criticized. However, the public still expresses special fears about the access others might have to their genomic information. In this article, it is argued that there may be a basis for the public perception that genomic information is special, even if it cannot be said that policies could or should be enacted to protect the privacy and confidentiality of genomic information that would be exceptional relative to the protections one would enact to protect other types of sensitive information. The special nature of genomic information lies in understanding that it is neither personal property nor mere information. A genome is, at one and the same time, a physical aspect of a person and information about that person. Genomic data are embodied information that partially constitutes as well as describes individuals and that connects them in physical ways to their ancestors and their relatives. All forms of privacy need to be protected, but some intimate aspects of our lives command special respect. To see a genome is more analogous to seeing a naked body than to seeing a social security number. This metaphor suggests that clinicians and investigators ought to respect the special concerns of patients regarding genomic information while not claiming that there are any exceptional measures one could take to protect genomic privacy. Suggestions are given for how this view might affect patient interactions, consent discussions, public policy, and public trust in genomic research and clinical genetics.

Genet Med advance online publication 18 September 2014

Key Words: confidentiality; ethics; genetics; genomics; policy privacy
As geneticists know well, the $\$ 1,000$ genome is almost a reality. ${ }^{1}$ Human genomic data are regularly used in research and clinical applications are beginning to emerge. ${ }^{2,3}$ Medical geneticists, counselors, and investigators see the great promise in these developments. Nonetheless, patients and the public have expressed special fears about the privacy of genetic information. $^{4-8}$ Some commentators have argued that this calls for exceptional privacy protections. Others have criticized this attitude as "genetic exceptionalism," noting that there are many kinds of sensitive information that require significant privacy protection, such as financial, sexual, psychiatric, and substance abuse histories. ${ }^{9-12}$ Worries about stigmatization and discrimination are real, but these commentators argue that there is no difference in kind between genomic and other kinds of information.

By contrast, I make a distinction between what can be considered special and what calls for exceptional rules and regulations. What I mean by saying that genomic information is special is that there are qualitatively distinct and important differences between genomic information and other kinds of information that justify the public's heightened sensitivity about genomic information and command particular respect on the part of clinicians and investigators. In saying that genomic information is not exceptional, however, I argue that all patient information deserves privacy protection and that there are practical limits on what one can do to protect the privacy of any form of patient information as a matter of public policy so that, in this sense, there is nothing unique about genomic information. I therefore argue that it is a mistake to say that there is nothing special about genomic information while simultaneously acknowledging that this may not require much that is exceptional in regulation and policy. This view calls for researchers, clinicians, and policy makers to acknowledge that there is a reasonable basis for the special concerns of patients and the public regarding genomic information and that they ought to attend to these concerns in their dealings with individual research subjects and patients, as well as be prepared to accept special laws and policies designed to protect genetic privacy, even if these policies only make explicit what should be true of all aspects of patient privacy. To insist that there is nothing special about privacy concerns surrounding genomic data might come across as supercilious or even reckless to individual patients and the public at large, and might risk creating a backlash. Nonetheless, the obligation to protect genetic privacy is best viewed as only one important part of a broader duty to protect the privacy of patients and the public. Analogous to the fact that although there is nothing exceptional that one can or ought to do to protect the privacy of a patient's naked body compared with other aspects of privacy that also ought to be protected, the intimacy of a patient's naked genome makes it a special privacy concern. 


\section{ARGUMENTS FOR GENETIC EXCEPTIONALISM HAVE BEEN UNCONVINCING}

Roche and Annas ${ }^{13}$ have argued in favor of genetic exceptionalism, suggesting that genetic data demand exceptional protection because such data simultaneously reveal information about a person's present state, potential future, and relatives. While true, however, these features do not justify claims that genomic data are unique or that public policy should treat genomic data exceptionally. These features would not distinguish genomic data from a databank containing a patient's current medical problem list, calculated risk for diseases based on clinical algorithms, and family members' names.

\section{TWO SPHERES OF PERSONAL PRIVACY: THE PHYSICAL AND THE INFORMATIONAL}

Privacy can be thought about as a limitation on the access others have to an individual person. Generally speaking, there are two spheres of privacy. One is physical-the right not to be intruded on or touched or searched or manipulated without consent. This physical privacy encompasses one's body, some surrounding zone, and one's property. The other sphere of privacy is informational-the right to prevent others from knowing certain things about oneself. People want assurances that they can choose what information goes where.

Privacy can be breached to protect others from harm, of course, or to protect the common good for reasons of security or public health. Yet deviations from the expectation of privacy must be justified, and, in a free society, the bar must be set high to justify a violation of privacy by the state.

\section{CONFIDENTIALITY}

Confidentiality may be defined as informational privacy held in trust. In revealing something private about oneself with the expectation that it not be revealed to others, one establishes the conditions of confidentiality. Clinicians and those involved in human subjects research have significant duties to protect the confidentiality of patients and research subjects.

So, with respect to genomics, privacy concerns relate to issues such as who will have access to genomic information that is stored in databases or access to tissue samples from which such information can be extracted. Confidentiality concerns the duty of clinicians and investigators not to disclose genomic information to third parties without the consent of the individual patient or research subject. Privacy and confidentiality concerns are particularly sensitive with respect to access that insurers or employers might have to genomic information.

I argue that part of what makes genomic information special is that it straddles the physical and the informational spheres of privacy and confidentiality. Genomes are not one's personal physical property or one's own person, nor are they merely information about oneself. Genomes are, at one and the same time, physical parts of each person, partially constitutive of each individual, and partly descriptive of that person. Moreover, genomes are both interpersonal and intergenerational in both the physical and informational ways. It is by understanding what genomes are and what they are not that one comes to appreciate what makes genomic information special, even if being special does not make it exceptional.

\section{PROPERTY?}

One form of physical privacy concerns property. It might be argued that genomes are private personal physical property, that people "own" their genomes the way they own their homes, thus forming the rational basis of claims for genetic privacy. The view that genomes are private physical property seems unwarranted. It is true that some have claimed that people "own" their organs, such as their livers and kidneys. Yet even if one were to hold that people own their organs and other body parts, one cannot claim that genomes are private property in the same way. First, genomes are not simply physical objects like organs. To the extent that one is claiming that genomes are body parts that can be owned, one might more properly say that people own their chromosomes just as they own their livers. Yet when a person says, "I own my genome," he or she is not talking about owning these subcellular structures, or even pictures of them. Genomes are parts of the body but are diffused throughout the body-molecular parts of each cell and each organ. Thus, whereas a kidney might be alienable in the sense that it can be taken out of oneself and given to another, genomes are neither alienable nor fungible. While eschewing the reductionism of claims that "we are our genes," it is still true that a genome is so integral to what and who one is that one cannot alienate one's genome from oneself without ceasing to be who one is. One can donate a kidney or even sell it (the ethics of such a practice notwithstanding), but one cannot "extract" one's genome from oneself and transfer it to another as his or her property rather than one's own without self-annihilation.

Second, most genes are so conserved that humans share 99.9\% of their genes with all other human beings and $99 \%$ with other mammals (with the codes of other primates' genes being approximately $96 \%$ the same as human codes and mouse gene codes being $85 \%$ similar)..$^{14,15}$ If this is so, it would seem impossible to adjudicate competing claims of ownership. One might counter by claiming that individuals own only the variable parts that are unique to them. Yet the part that is unique is just a small fraction of the genome, and much of it is in unexpressed regions or is defective. That hardly sounds like property anyone wants to own.

Genomes thus cannot be considered private personal physical property. They cannot be transferred from one "owner" to another, and they are largely part of a common human patrimony over which no individual can claim exclusive dispositional rights.

Another form of property is not physical but informational. One might advance the claim that genomes are better thought of as information than as objects, and so advance privacy claims by arguing that genomes are intellectual property. But this view does not seem right either. Genomes are given, not made. Genomes are not created as novel substances that anyone can claim to own as intellectual property. Even the idea that 
someone has exerted intellectual labor in order to sequence an individual's genome does not seem sufficient to justify the claim of ownership. People rightly would object to the idea that someone else would own their genomes upon sequencing them. Nor could patients make claims to ownership of their genomes as intellectual property because the vast majority will never sequence their own genomes. The normal sequences of common functional human genes are part of common human biology, like human enzymes, cell types, tissues, and organs; such sequences can be described but are ultimately discoveries rather than novel creations warranting consideration as intellectual property. ${ }^{16-20}$ Moreover, the idea that genes can be patented as intellectual property has been rejected by the US Supreme Court. ${ }^{21}$ And certainly, if genes were deemed patentable, these patents would not belong to the patients whose genes they are; therefore, patent law could not provide a basis for patients' genetic privacy claims.

\section{SENSITIVE INFORMATION?}

There seems no way, then, to justify special privacy claims for individuals' genomes by arguing that genomes are either physical or intellectual property. If this is so, perhaps the critics are right to say that individual genomic data are just one kind of information that ought to be protected by informational privacy standards, differing only, perhaps, in the degree of sensitivity with which such information should be regarded but not understood as qualitatively special. For instance, medical records contain all kinds of sensitive information that ought not to be divulged without extraordinarily serious justification. The genomic era, perhaps, gives one more reason to underscore the importance of the Hippocratic duty to maintain confidentiality. Physicians have a duty to hold genomic information in confidence, but there is nothing more special about it than other personal information.

One may rightly ask then, why genomic information evokes such special privacy concerns among so many people. Perhaps a clue lies in the simple idea that all sensitive information is not the same. And if that is the case, thinking more carefully about what is distinctive about genomic information will be necessary.

\section{WHAT IS A GENOME?}

Much to the chagrin of geneticists, the terms "gene" and "genome" are often bandied about in discussions of bioethics and health policy without a clear understanding of their meanings. Such discourse is plagued by simplistic metaphors and reductionistic thinking. ${ }^{22}$ It seems hard to imagine that society will ever get its ethics and policies right, however, if the concepts at issue are unclear.

A genome can be defined as "the heritable information, specified in nucleic acid sequences, upon which an organism draws in generating its phenotypic response (through the production of peptides or the regulation of their production) in specific cellular, organismal, developmental, phylogenetic, and ecological contexts."23
This definition is hardly mystical. It is neither reductionistic nor deterministic. Although even terms such as "information" can still be considered metaphorical, what emerges from reflection upon this formal definition is the idea that a genome is not just information. A human genome is information, but it is unlike any other information about human beings. Human genomes are, at one and the same time, physical biological parts of persons as well as unique data about those persons. Genomic information is physically specified in molecular patterns within each individual. A genome is neither just information nor just a physical molecular structure. It is an informed molecular structure that is heritable, relational, and contextual.

Genomes are information about individuals, but they also are physically part of those individuals. Genomes are information that is encoded in persons. Genomes are partly constitutive of who and what they are. Genomes are in persons, but they are also dissociable from persons. Genomes are partly about persons and partly help to form persons. For another individual to have access to a person's genome means that someone else has knowledge not just about that person but also of that person.

Genomes contain information about a person's ancestors and relatives, but, more than that, genomes are also a physical connection to that person's ancestors and relatives. Genomes are not merely information that one's parents have passed down through communication. Genomes are the physical result of parental genes combining and recombining to form each person. A genome is, in part, one's ancestry and one's family encoded in one's physical being.

Genomes contain information about one's possible future and about one's finitude. But genomes do not merely inform one of the truth of the propositions that one will suffer and that one will die. Genomes provide clues about how and when one might suffer and how and when one might die.

It is only a vanishingly small percentage of DNA that distinguishes individual human beings from each other, yet that variety is critical to the distinctiveness of persons. It has been argued that once people came to understand that everyone has, on average, between 9 and 25 significant mutations, people would just get over their irrational fears about the privacy of genetic information-that it would all "wash out in the laundry." ${ }^{24}$ As the era of whole-genome sequencing dawns, however, that change in attitude does not seem to have occurred. ${ }^{4-8}$ If anything, fears seem to be heightened. Perhaps this is because although each person might have nine different mutations, there will be a certain nine of which each person will say, "These are $m y$ nine mutations." When a person's genome is sequenced, it will be his or her unique scars that have been exposed. That person's own imperfections, finitude, vulnerabilities, and risks will have been uncovered.

\section{NAKED BODIES, NAKED GENOMES}

When others see one's genome, they are, in a sense, seeing one naked. Even if the purpose of much of the DNA in the human genome is not understood, if other persons have access to one's genome, then one will have been exposed in a way that is at 
once physical and informational. To be so exposed before the genetic gaze of a stranger is to be in a position of grave personal vulnerability. A voice from somewhere may then be asking, "Who told you that you were naked?" (Genesis 3:11). To see someone's genome is to see that person's past and future and relations and finitude, not just in an informational sense but also in an embodied sense. Genomic information is not just information about persons but also information that partly forms persons. In a strong sense, genomes are part of each person, and they help to constitute who, as well as what, each person is. Accordingly, it should not seem surprising that people reach for the ancient fig leaf of privacy to be sure that others do not see their genomes without explicit permission. People wish to protect themselves from the intimacy of this genetic gaze upon the naked, embodied truth of them.

Some might object to this metaphor, arguing that genes cannot be seen immediately the way a body can be seen. The phrase, "genetic gaze," however, draws its inspiration from Foucault's richly suggestive idea of the "clinical gaze."25 Just as Foucault argues that in the 18th century physicians began to "see" in their living patients the anatomical pathology of the dead, today clinicians, investigators, and even entrepreneurs can be said to "see" a genome when they see a patient. To be sure, both anatomical pathology and genomics require material manipulation and interpretation rather than immediate-sense knowledge, but the interpersonal effect of such seeing is the generation of a kind of knowledge that might even surpass the intimacy and significance of seeing a naked body - a gaze that penetrates the skin to reach what is understood to be the "real" embodied truth of the person.

People are aware of the promise that genomic research might hold for them, the good that might come from others knowing about their genomes. Accordingly, just as patients allow physicians to see their naked bodies in order to help them, patients are beginning to allow physicians to see their naked genomes in order to help them. In the clinical encounter, however, patients have significant expectations regarding this exposure. They expect to be given a gown to cloak them when they visit their physicians. They expect that photos of their naked selves will not be spread around the Internet for voyeuristic purposes or for others' profits. It should not be surprising that people have similar expectations regarding the privacy of their genomes.

\section{THE UNIQUENESS OF PRIVACY CONCERNS REGARDING GENOMIC INFORMATION}

Privacy concerns regarding genomic information are not unique in medical practice and human subjects research. Medicine needs to protect the informational privacy of patients and research subjects as well as the physical privacy of their bodies, persons, and property. In this sense, genetic exceptionalism is false. There is little that can be done to protect genetic privacy that ought not to be done to protect other types of biomedical information.

Nonetheless, the way genetic information straddles both the informational and the physical spheres of privacy-the way genetic information is related both to persons' constitutions as the kinds of things that they are and to their individualitydoes make personal genomic information seem different from other sensitive information. Thus, when the public expresses special concern regarding the privacy of genetic information, such concern should not be dismissed lightly or be regarded as having little rational basis. Genomes have a special relationship to who each individual is as an embodied person.

\section{BEYOND THE CONSEQUENCES}

To claim that genetic information is especially sensitive does not necessarily entail that breaches of genomic confidentiality involve worse consequences than breaches of confidentiality about other sensitive information. Genomes can certainly be misused-replicated, transmitted around the world, manipulated, or sold-as can other sensitive information. The point is that the harms that could result from such actions do not devolve solely from the consequences of the actions, such as discrimination or loss of insurance coverage or being targeted for a special marketing campaign. Rather, such abuses would constitute harms to persons independent of the consequences. The recent revelation that it is possible to identify individuals on the basis of their "deidentified" genomic data serves as a case in point. ${ }^{26}$ There was widespread negative reaction and alarm despite the fact that no negative consequences befell those who were reidentified. ${ }^{27}$ The bare fact that these individuals were reidentified ("unclothed," so to speak) itself constituted the harm. It is not unreasonable to demur at the thought that just anyone might be able to gaze at one's naked genome. It thus seems reasonable that medicine should be especially concerned about the privacy of genomic information. This is not to say that the consequences that could be associated with breaches of genomic privacy might not be greater than those associated with breaches of the privacy of a naked body. Rather, it is to say that the naked body metaphor helps one understand why genomic information has a special salience beyond the consequential importance that genomic information shares with other types of sensitive information.

\section{IMPLICATIONS}

The idea that genomic information is truly special-even if the regulations protecting it cannot be considered exceptional as compared with regulations and policies regarding other kinds of sensitive information-has several concrete implications. First, the metaphor of nakedness may help clinicians and investigators to show the kind of special respect for privacy that genomic data warrant. Not all privacy concerns are the same. We close the door to protect the privacy of conversations, but we gown patients and veil them behind curtains as well as close the door when they are naked. Even though we have a duty to protect all aspects of privacy, some privacy concerns are just more intimate than other privacy concerns, and respect for persons demands attention to such nuances. Second, in both clinical and research settings, this view will affect attempts to assuage fears and obtain truly informed consent from patients and research subjects. 
Clinicians and investigators should not say, as the standard anti-exceptionalist view would have it, "You should not worry. There is nothing really different about genomic information compared with giving us your social security number. We will keep both in confidence." Rather they should say, "We appreciate that genomic information is especially sensitive. That is why we are so grateful that you are permitting us to have access to this information and why we are so committed to protecting your confidentiality as rigorously as we can." The difference may seem subtle, but it is significant. In the long run, the second approach will do much more to foster trust. Third, although it is difficult to see how policies would be very different under the special but not exceptional view, the fact that there is a law such as the Genetic Information Nondiscrimination Act calls attention to the special nature of genomic information. ${ }^{28}$ The Genetic Information Nondiscrimination Act, in fact, requires little that should not be standard about how the confidentiality and privacy concerns surrounding other kinds of sensitive information should be addressed but reassures the public at large, as well as patients and potential research subjects, by spelling out a plan to address the seriousness of concerns regarding genetic discrimination in a special way. Some ethicists and scientists bristle at the thought of special genetic regulations, complaining that public health and the progress of science will be hampered, and arguing that, for the common good, genomic data should be treated as public data, much like the cause of death on a death certificate. ${ }^{29,30}$ Special policies about genomic data, however, should not be denigrated as unnecessary exceptionalism. Provided that the requirements are reasonable and fair, such regulations should be championed by the research and clinical communities in genetics as advocates for the morally best in patient care and research. Fourth, gaps in legal protection for genetic privacy should be addressed through policy. One good example would be to set limits on the access law enforcement officials have to genomic information (such as race, disease dispositions, or other factors) beyond what is needed to verify the genetic match of an individual suspect with a crime scene sample. The scope of forensic genomics should be strictly delimited and held subject to appropriate judicial supervision. ${ }^{31}$

\section{CONCLUSIONS}

There are impressive possibilities to be realized in harnessing the power of the human genome. But investigators and clinicians will need to provide subjects and patients with the broad fig leaf of privacy upon asking them to reveal their genomes. In its recent report on ethics and whole-genome sequencing, the Presidential Commission for the Study of Bioethical Issues recognized that the best way to realize the potential benefit of the new genomics is to protect patient privacy vigorously. ${ }^{31}$ If the biomedical community insists that there is "nothing special" about genomic privacy, ${ }^{10}$ scientific progress may be impeded because of a failure to understand the justifiable fears of the wider public. If, however, investigators and clinicians are able to understand the rational basis for such concerns, be respectful of them, and provide the vigorous privacy protections that such concerns warrant, then they will have established the firm ethical foundations upon which genomic medicine can be built.

\section{ACKNOWLEDGMENTS}

The views expressed are those of the author and do not necessarily represent those of the Presidential Commission for the Study of Bioethical Issues or the government of the United States.

\section{DISCLOSURE}

The author declares no conflict of interest.

\section{REFERENCES}

1. Hayden EC. Technology: the $\$ 1,000$ genome. Nature 2014;507:294-295.

2. Bainbridge MN, Wiszniewski W, Murdock DR, et al. Whole-genome sequencing for optimized patient management. Sci Trans/ Med 2011;3:87re3.

3. Multiple-System Atrophy Research Collaboration. Mutations in COQ2 in familial and sporadic multiple-system atrophy. N Engl J Med 2013;369:233-244.

4. Lemke AA, Wolf WA, Hebert-Beirne J, Smith ME. Public and biobank participant attitudes toward genetic research participation and data sharing. Public Health Genomics 2010;13:368-377.

5. Melas PA, Sjöholm LK, Forsner T, et al. Examining the public refusal to consent to DNA biobanking: empirical data from a Swedish population-based study. J Med Ethics 2010;36:93-98

6. Ruiz-Canela M, Valle-Mansilla Jl, Sulmasy DP. What research participants want to know about genetic research results: the impact of "genetic exceptionalism". J Empir Res Hum Res Ethics 2011;6:39-46.

7. Trinidad SB, Fullerton SM, Bares JM, Jarvik GP, Larson EB, Burke W. Genomic research and wide data sharing: views of prospective participants. Genet Med 2010;12:486-495.

8. Kaufman DJ, Murphy-Bollinger J, Scott J, Hudson KL. Public opinion about the importance of privacy in biobank resvaearch. Am J Hum Genet 2009;85:643654.

9. Murray TH. Genetic exceptionalism and 'future diaries': is genetic information different from other medical information?" In Rothstein MA (ed). Genetic Secrets: Protecting Privacy and Confidentiality in the Genetic Era. New Haven, CT: Yale University Press, 1997:60-73.

10. Holm $\mathrm{S}$. There is nothing special about genetic information. In Thompson AK, Chadwick RF (eds). Genetic Information: Acquisition, Access and Control. New York: Kluwer Academic/Plenum, 1999:97-104.

11. Gostin LO, Hodge JG. Genetic privacy and the law: an end to genetics exceptionalism. Jurimetrics 1999;40:21-58.

12. Green MJ, Botkin JR. "Genetic exceptionalism" in medicine: clarifying the differences between genetic and nongenetic tests. Ann Intern Med 2003;138:571-575.

13. Roche PA, Annas GJ. Protecting genetic privacy. Nat Rev Genet 2001;2:392396.

14. Koshland Science Museum, National Academy of Sciences. Tracing similarities and differences in our DNA. https://www.koshland-science-museum.org/sites/ all/exhibits/exhibitdna/intro03.jsp. Accessed 10 April 2014.

15. National Human Genome Research Institute. Comparative genomics. https:// www.genome.gov/11509542. Accessed 10 April 2014.

16. Cahill LS. Genetics, commodification, and social justice in the globalization era. Kennedy Inst Ethics J 2001;11:221-238.

17. Kluge EH. Patenting human genes: when economic interests trump logic and ethics. Health Care Anal 2003;11:119-130.

18. Andrews LB, Paradise J. Gene patents: the need for bioethics scrutiny and legal change. Yale J Health Policy Law Ethics 2005;5:403-412.

19. Cho M. Patently unpatentable: implications of the Myriad court decision on genetic diagnostics. Trends Biotechno/ 2010;28:548-551.

20. Nowotny H, Testa G. Naked Genes: Reinventing the Human in the Molecular Age. Trans. Cohen M. Cambridge, MA: MIT Press, 2010:39-42.

21. Association for Molecular Pathology et al. v. Myriad Genetics, Inc, et al. 569 US (2013).

22. Moss L. What Genes Can't Do. Cambridge MA: MIT Press, 2004.

23. Sulmasy DP. The logos of the genome: genomes as parts of organisms. Theor Med Bioeth 2006;27:535-540.

24. Barash Cl. Just Genes: The Ethics of Genetic Technology. Santa Barbara, CA: Greenwood, 2008:21 
25. Foucault M. The Birth of the Clinic: An Archaeology of Medical Perception. Trans Smith MAS. New York: Vintage, 1994:51-63.

26. Gymrek M, McGuire AL, Golan D, Halperin E, Erlich Y. Identifying persona genomes by surname inference. Science 2013;339:321-324.

27. Kolata G. Online hunt for DNA compromises privacy. New York Times. 18 January 2013, A15.

28. Genetic Information Nondiscrimination Act, 122 Stat, 2008:881-922.
29. Hodge JG Jr. Ethical issues concerning genetic testing and screening in public health. Am J Med Genet C Semin Med Genet 2004;125C:66-70.

30. McCall B. European Parliament supports data protection reforms. Lancet 2014;383:1115.

31. Presidential Commission for the Study of Bioethical Issues. Privacy and Progress in Whole Genome Sequencing. Washington, DC: Presidential Commission for the Study of Bioethical Issues, 2012. 